\title{
Levels of Anxiety and Quality of Life in Overweight Individuals Under Nutritional Monitoring
}

\author{
Géssika Dutra de Andrade Reis ${ }^{1}$, Virgínia Souza Santos ${ }^{2 *}$ and Martha Elisa Ferreira de Almeida ${ }^{2}$ \\ ${ }^{1}$ Nutritionist by Federal University of Viçosa (UFV), Brazil \\ ${ }^{2}$ Nutrition Course, Federal University of Viçosa (UFV), Brazil \\ ${ }^{3}$ Prof. of the Nutrition Course, Federal University of Viçosa (UFV), Brazil
}

*Corresponding author: Virgínia Souza Santos, Federal University of Viçosa (UFV), Rio Paranaíba Campus, Brazil

Submission: 望 January 30, 2018; Published: 眥 February 23, 2018

\begin{abstract}
Summary
Being overweight is directly related to the high level of anxiety and the poor quality of life. The objective of the study was to verify the levels of anxiety and quality of life in overweight adults submitted to nutritional monitoring. Anxiety levels were assessed by applying the Inventory "The Mind Overcoming Mood" and Quality of Life using WHOQOL-bref instrument, as well as socioeconomic and demographic characteristics. For the comparison of the scores of each domain by gender the Student's T Test was used, and the four domains in the genres were used and in general the Tukey's test was used, both at 5\% significance. The majority of the patients were females (84.85\%, n=28) and had an average Body Mass Index of $32.57 \pm 4.75 \mathrm{~kg} / \mathrm{m}^{2}$, classified as obesity class 1 , anxiety was $21.88 \pm 11.68$ points, with the women presenting the highest mean. Among the interviewees, $57.6 \%(n=19)$ considered their quality of life to be "good". The best scores obtained by the WHOQOL-BREF were in the Social (73.48) and Physical (68.29) domains. There was a significant difference $(p<0.05)$ in genders, only in the Psychological domain. In the evaluation of the domains, in the female gender and in the general evaluation, the Social domain had a higher mean score ( $<<0.05)$ than the Psychological and Environmental domains, and in the male gender there was no significant difference between the mean scores between the domains. It was concluded that the majority of the patients presented obesity class 1, and in the female gender there was a higher anxiety score and lower quality of life in the psychological domain. It is suggested that other studies are conducted to analyze the influence of anxiety on the treatment of excess weight, as well as the impact of reducing body weight on the quality of life of these patients.
\end{abstract}

Key words: Lifestyle; Obesity; Nutritional Evaluation

\section{Introduction}

Obesity is a chronic disease of multifactorial origin, resulting from genetic, physiological, environmental and psychological factors, which causes excessive accumulation of energy in the form of fat in the body, which can generate serious risks to health and quality of life. [1]. Overweight is a global health problem that affects approximately 1.9 billion adults, accounting for $29 \%$ of the world's population [2]. In Brazil, overweight accounts for $53.8 \%$ of Brazilians, with $18.9 \%$ being obese [3]. Obesity is associated with several psychological problems such as altered self-concept, negative self-assessment, self-image distortion, depression and anxiety [4]

Anxiety occurs as a result of emotional reactions to genetic and environmental factors, and acts as a mechanism of surveillance of the body to alert it of possible dangers, playing a protective role in preserving the individual. It can become pathological when there is an inadequate judgment of the danger of a certain moment, bringing losses in the daily social and occupational functioning of the individual $[5,6]$. Obese patients seek to eat an alternative to reduce anxiety, which may result in weight gain proportional to the frequency of anxiety episodes. The continuity of this process of anxiety and relief when feeding becomes a vicious circle that can result in binge eating and favor the onset of obesity [7].

Changes in eating habits have been seen by overweight individuals as radical interventions, which are usually associated with poor quality of life. Such patients are eager for changes in eating behavior to obtain rapid results, however, eating habits need to be reconstructed and incorporate the routine of the individual gradually, a fact that requires time to be determined according to individual evolution [8].

Health professionals should evaluate overweight patients to diagnose and treat early those with signs and symptoms of psychiatric disorders, since anxiety in these patients correlates with a more difficult intervention. The psychological component in overweight people requires therapy with the use of drugs (antidepressants, anti-anxiety or antipsychotics) or specific psychotherapies to help them with their feelings/frustrations without using overeating [6]. Quality of life and health are strongly interrelated phenomena, since health positively influences quality 
of life, and is directly related to good habits acquired throughout life [9].

Quality of life (QOL) was defined in 1994 by the World Health Organization as "the individual's perception of their position in life, in the context of the culture and value system in which they live and in relation to their goals, expectations, standards and concerns [10].

The epidemiological and nutritional transitions promote the growth of nutritional problems and compromise the quality of life, contributing to the early and frequent onset of chronic noncommunicable diseases such as obesity [11].

Low levels of quality of life are directly linked to overweight [12], and may be associated with anxiety disorders, and a greater severity of anxiety symptoms will be correlated with a lower quality of life of the individual [13].

The objective of the study was to verify the levels of anxiety and quality of life in overweight adults, attended at the Nutritional Care Outpatient Clinic of the Federal University of Viçosa, Rio Paranaíba Campus, Minas Gerais, Brazil.

\section{Methods}

This was a quantitative, observational and descriptive study, carried out at the Nutrition Care Clinic of the Federal University of Viçosa, Rio Paranaíba Campus (MG), after approval of the Ethics and Research Committee with Human Beings of the Federal University of Viçosa, protocol number 078170/2016. Were included individuals between 19 and 59 years of age, both genders, overweight and obese, underwent nutritional monitoring to reduce body weight, from March to May 2017. Not included individuals who were under follow-up psychological and psychiatric, since such a factor could directly interfere in the anxiety levels of those surveyed.

After the nutritional consultations, the patients were invited to participate in the research and to answer questionnaires about their socioeconomic and demographic characteristics, nutritional status, level of anxiety and quality of life. A semi-structured questionnaire with 22 questions was used to assess socioeconomic and demographic characteristics. Nutritional status was assessed using the Body Mass Index (BMI), which was classified according to the World Health Organization [2].

The anxiety symptoms were verified by the Anxiety Inventory "The Overcoming Mood", which is composed of a self-applied scale with 24 questions to measure the evolution of the symptomatology of anxiety. The total score was obtained by summing the points, with the highest results associated with anxiety symptoms [14]. To analyze the quality of life was used the WHOQOL-BREF instrument, validated for the Brazilian population [15], was composed of 26 questions involving the Physical, Psychological, Social Relations and Environment domains, and allows the subjective evaluation of the degree of satisfaction of the individual with his or her life. The responses were evaluated by a Likert-type scale ( 1 to 5 points), in which the higher the score defined a better quality of life of the evaluated $[15,16]$.
Statistical analysis was performed in the Statistical Package for Social Science (SPSS), version 20.0. For the evaluation of the comparison of the scores of each domain, by gender, the Student $\mathrm{T}$ Test was used, and for the comparison of the 4 domains in the genres and in the total, the Tukey test was adopted, both at $5 \%$ significance.

\section{Results}

Thirty-three individuals with a mean age of $35.88 \pm 10.66$ years participated in the study, of which $84.85 \%(n=28)$ were females. Among those evaluated, 51.52\% ( $\mathrm{n}=17)$ were married; $57.58 \%$ $(n=19)$ had children, with a mean of 2.16 children per patient. Regarding monthly family income, $57.59 \%(\mathrm{n}=19)$ received from 2 to 3 minimum wages, and $33.33 \%(n=11)$ received up to 1 minimum wage. The average number of people living in the household was 3.12 people. In the evaluation of schooling, $30.30 \%(n=10)$ finished elementary school and $27.27 \%(n=9)$ high school.

On a weekly basis, those evaluated had an average of 17.85 hours of work, and $51.52 \%(n=17)$ were retirees, students and the home, and did not perform labor activities.

Of those interviewed, 63.63\% $(n=21)$ used food supplements (multivitamins) and medicines to control systemic arterial pressure, hypoglycemic agents, contraceptives, Simvastatin and Omeprazole. The use of drugs for weight loss was cited by $15.15 \%$ $(n=5)$, especially Orlistate, Topiramate and Sibutramine. For the control of anxiety, 9.09\% (n=3) of the patients used Fluoxetine.

In the analysis of the current clinical history, $81.82 \%(n=27)$ of the patients mentioned anxiety symptoms. This fact was presented by $80 \%(n=4)$ of males and $82.14 \%(n=23)$ of females. Among the women, 9 of them (32.14\%) reported the presence of insomnia, however the average sleep of the evaluated ones was 7.67 hours. It was observed that $21.43 \%(n=6)$ of the women reported having depressive signs.

The majority of the analyzed $(78.79 \%, \mathrm{n}=26)$ mentioned having already followed a diet, and only $65.38 \%(n=17)$ received guidance from a nutritionist. The practice of physical activity was performed by $57.58 \%(n=19)$ of the patients, in which $36.84 \%$ ( $n=7$ ) practiced 3 to 4 times a week. Activities such as water aerobics, walking, soccer, fights, dancing and cycling were mentioned. None of the evaluated subjects were smokers; however, $33.33 \%(n=11)$ reported being drinkers, and $80 \%(n=4)$ men and $25 \%(n=7)$ women used such beverages at social events or with other people.

As to the reason for the nutritional consultation, 96.97\% (n=32) sought to reduce their body weight, and the others to improve pathologies associated with obesity. Nutritional care was cited by $81.81 \%(n=27)$ of those evaluated, and the others were influenced by family members or medical referral.

The mean BMI presented by the evaluated individuals was $32.57 \pm 4.75 \mathrm{~kg} / \mathrm{m}^{2}$, where $42.86 \%(\mathrm{n}=12)$ of the female gender presented obesity class 1 , and $40 \%(\mathrm{n}=2)$ of the male presented obesity class 2 (Figure 1). The classification of obesity class 3 was identified in $9.09 \%(n=3)$ of those evaluated, and this fact is one of 
the risk factors for higher levels of anxiety and lower quality of life (Figure 1).

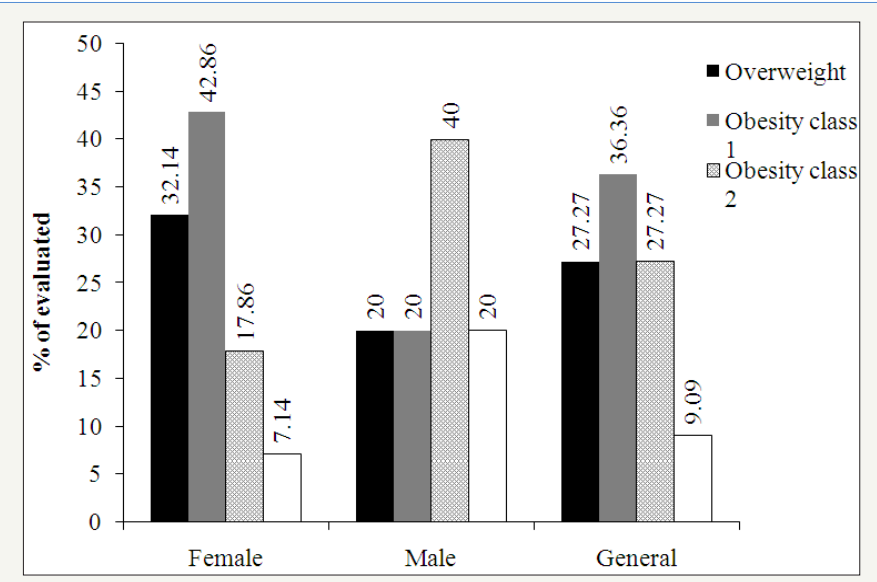

Figure 1: Relative frequency, according to gender, regarding the classification of the nutritional status of patients under nutritional monitoring, Rio Paranaíba, Minas Gerais, Brazil, 2017.
Regarding the anxiety scores, the mean was $21.88 \pm 11.68$ points, with the minimum and maximum values of 2 and 45 points, respectively. The female gender had a higher mean of the anxiety scores $(26.68 \pm 11.33$ points), when compared to the male gender (13.25 \pm 8.76 points). The most frequent anxiety symptoms were nervousness $(93.94 \%, n=31)$, continuous concerns $(84.85 \%, n=28)$, irritability $(78.79 \%, n=26)$, and the least was difficulty swallowing or ball in the throat $(15,15 \%, n=5)$.

Regarding patients' quality of life, the majority evaluated it as good (57.6\%, $n=19)$; however, 60.61\% $(n=20)$ reported not being satisfied with their health. The best average quality of life scores were presented in the Social (73.48) and Physical (68.29) domains.

There was a significant difference $(\mathrm{p}<0.05)$ in genders, only in the psychological domain. In the evaluation of the domains, in the female gender and in the general evaluation, the Social domain had a higher mean score $(\mathrm{p}<0.05)$ than the Psychological and Environmental domains, and in the male gender there was no significant difference between the mean scores between the domains (Table 1).

Table 1: Distribution of the mean scores of the quality of life domains, according to gender, of the patients under nutritional monitoring, Rio Paranaíba, Minas Gerais, Brazil, 2017.

\begin{tabular}{|c|c|c|c|c|c|c|c|c|c|}
\hline Gener & Physical & p Value $†$ & Psychological & p Value $\dagger$ & Social & p Value $\dagger$ & Environmental & p Value $\dagger$ & p Value $\neq$ \\
\hline $\begin{array}{l}\text { Female } \\
(\mathrm{n}=28)\end{array}$ & $\begin{array}{c}68,75 \\
\pm 16,88^{\mathrm{ab}}\end{array}$ & \multirow{3}{*}{0,708} & $\begin{array}{c}57,74 \\
\pm 13,74^{\mathrm{a}}, *\end{array}$ & \multirow{3}{*}{0,016} & $\begin{array}{c}73,62 \\
\pm 19,21^{\mathrm{b}}\end{array}$ & \multirow{3}{*}{0,494} & $\begin{array}{c}61,16 \\
\pm 12,57^{\mathrm{a}}\end{array}$ & \multirow{3}{*}{0,204} & 0,001 \\
\hline Male (n=5) & $65,71 \pm 14,20$ & & $74,17 \pm 9,95^{*}$ & & $80,00 \pm 17,28$ & & $68,75 \pm 7,65$ & & 0,341 \\
\hline $\begin{array}{c}\text { General } \\
(\mathrm{n}=33)\end{array}$ & $\begin{array}{c}68,29 \\
\pm 16,34^{\mathrm{ab}}\end{array}$ & & $\begin{array}{r}60,23 \\
\pm 14,40 \mathrm{a}\end{array}$ & & $\begin{array}{c}74,59 \\
\pm 18,81^{\mathrm{b}}\end{array}$ & & $\begin{array}{c}62,31 \\
\pm 12,18^{\mathrm{a}}\end{array}$ & & 0,001 \\
\hline
\end{tabular}

$\dagger p$ value analyzed by Student's Test between genders in column.

*Demonstrates difference between genders in the domains.

$\ddagger p$ value analyzed by the Tukey test between the domains, in the row. Different letters on the line show statistical difference between domains

\section{Discussion}

In this study there was a higher prevalence of female subjects seen at the Nutritional Care Outpatient Clinic, as observed in other studies [17]. This fact has been justified by the high concern of this public with their body, resulting in a greater demand for health services [18].

The mean BMI presented by participants was $32.57 \pm 4.75 \mathrm{~kg} /$ $\mathrm{m}^{2}$. The majority $(63.63 \%, \mathrm{n}=21)$ reported that they used vitamin supplements and medications to control chronic noncommunicable diseases such as systemic arterial hypertension, diabetes mellitus and dyslipidemia, which are directly linked to obesity. The importance of nutritional treatment based on food education can change dietary habits that may result in well-being and decrease the development of pathologies associated with overweight [17].

Regarding the use of drugs to lose weight, $15.05 \%$ of the patients reported their use. In the study by Oliveira et al. [19] where discourses of women using Sibutramine to control body weight were analyzed, it has been observed that patterns of beauty throughout history have led the female audience to make various diets without being aware of the harm caused by the drug they own use.

Symptoms of anxiety and psychological distress were identified, being highlighted by Turcato et al. [20] that obese patients usually present greater psychological distress and emotional vulnerability, and higher means in the depression dimension and higher frequency of symptoms of depression at the clinical level.

Anxiety is part of human development, being an emotional state with physiological and psychological components, in which all people feel it in situations that generate insecurities, causing fear, apprehension and anticipation of unknown facts. When the anxiety occurs in an intense way, being disproportionate the situation or stimulus, it causes the blockade of the reasoning, and it prevents that daily activities are realized, happening to be recognized like pathological anxiety [21].

Patients did not have high levels of anxiety according to the adopted assessment instrument, although $81.82 \%(n=27)$ reported 
anxiety symptoms. The symptoms of anxiety are more present in obese individuals, making them more prone to the development of eating disorders with direct relation to Body Mass Index (BMI) [21]. A high level of anxiety may result in obesity, which requires a diet plan and physical activity, with psychological counseling $[7,21]$.

When comparing mean anxiety scores by gender, women presented higher levels of anxiety compared to men, as identified in other studies [22,23]. This fact may be correlated with high female exposure to stressful conditions, which increase anxiety levels, such as lower self-esteem, lower socioeconomic level, lack of energy, overload of functions, and psychological characteristics. The low anxiety score in men may be associated with the difficulty of diagnosis, since such individuals tend to deny their feelings, often replacing them with behaviors and attitudes such as irritation, aggression, antisocial attitude, hostility and misuse of alcoholic beverages [24].

In this study, 60.61\% $(\mathrm{n}=20)$ of those evaluated were not satisfied with their health, and $87.88 \%(n=29)$ reported negative feelings such as moodiness, anxiety, despair and depression. Obese patients need interventions that direct their goals for personalized treatments, focusing on the individuality of each individual, their personality characteristics and especially their psychological state, as this is an important indicator for clinical decision making, since they are vulnerable to suffering expressed in a wide variety of psychopathological symptoms [22].

Regarding physical appearance, $42.85 \%(n=12)$ women were dissatisfied with their image. Obesity is perceived not only as a condition that damages physical health, social and work life, but also generates suffering due to dissatisfaction with body image, loss of self-esteem and problems of discrimination, social exclusion and isolation. The perception of the overweight patient is linked to the society's view of them, which is often negative in appearance [25].

In this study, the best domain of quality of life was found in the Social area, however, obesity can reinforce feelings of depreciation, devaluation and shame, leading the individual to experience humiliating situations, isolation and social withdrawal. The valuation that a person confers on him, allowing him to have confidence, is shaped during life as a product of the interactions between the subject, the family and society, and can interfere in the physical and mental health of individuals, with repercussions on social life and affective, and on self-esteem, well-being and quality of life [26].

During consultations with health professionals, it is essential that nutritionists and other health professionals attend to the association between quality of life, anxiety and obesity. Nutritional education must be realistic, malleable, open to discussions in which the patient will be able to make his / her own choices in different situations, taking into account the physiological and psychological implications of eating. The reduction of body weight, even when small, significantly improves psychological well-being and quality of life, however there is no evidence that one behavioral strategy is superior to another to generate weight reduction, but it has been emphasized that multimodal strategies are more effective [7]. However, behavioral changes related to the nutritional aspect are more difficult to achieve, justifying the low adherence to treatments with nutritional interventions [8].

Patients with excess body weight have psychological vulnerability, which may affect their quality of life. It is highlighted [27] that the treatment of overweight and obesity in adults makes it essential that nutritional services have multidisciplinary assistance and seek to improve physical conditions, psychic and social. The services provided by Nutrition Outpatient clinics are of great social importance, since they provide the patients with an individualized and continuous nutritional follow-up, promoting the improvement of the nutritional profile that can reduce non-transmissible chronic diseases due to excess body weight [19].

\section{Conclusion}

Most of the evaluated patients presented obesity class 1 . Concerning anxiety, although many reported their symptoms, the scores were not elevated. In the general evaluation of the quality of life, the highest averages were found in the Physical and Social domains. The patients presented in the Social domain a higher average than the Psychological and Environmental domains, and higher anxiety score when compared to the men.

It is suggested that other studies are conducted to analyze the influence of anxiety on the treatment of excess weight, as well as the impact of reducing body weight on the quality of life of these patients.

\section{References}

1. World Health Organization (2018) Self-help strategies for cutting down or stopping substance use.

2. World Health Organization-WHO (2018) Obesity and overweight.

3. Vigitel Brasil (2018) Habits of Brazilians impact on the growth of obesity and increase prevalence of diabetes and hypertension.

4. Lofrano-Prado MC, Antunes HKM, Prado WL, Piano A, Caranti DA, et al (2009) Quality of life in Brazilian obese adolescents: effects of a longterm multidisciplinary lifestyle therapy. Health Qual Life Outcomes 7(61): 1-8.

5. Clark DA, Beck AT (2012) Terapia cognitiva para os transtornos de ansiedade: ciência e prática. Porto Alegre: Artmed.

6. Pereira C, Brandão I (2014) Uma perspectiva da psicopatologia da obesidade. Arq Med 28(5):152-159.

7. Associação Brasileira para o Estudo da Obesidade e da Síndrome Metabólica (2016) Diretrizes Brasileiras de Obesidade/ABESOAssociação Brasileira para o Estudo da Obesidade e da Síndrome Metabólica. 4. ed. São Paulo.

8. Goncalves ISA, Ferreira NTMY, Reis PVS, Pena GG (2015) Intervening factors in the follow-up of nutritional treatment for weight reduction in women attended at a basic health unit in Brazil. Rev Cuid 6(1): 914-922.

9. Veiga C, Cantorani JRH, Vargas LM (2016) Quality of life and alcoholism: a study in undergraduate students in physical education. Conexões14(1): 20-34.

10. Whoqol Group (1994) The development of the World Health 
Organization quality of life assessment instrument (the WHOQOL). In: Orley J, Kuyken W (Eds.). Quality of life assessment: international perspectives. Heidelberg: Springer Verlag 1994: 41-60.

11. Mais LA, Domene SMA, Barbosa MB, Tadei JAAC (2015) Formação de hábitos alimentares e promoção da saúde e nutrição: 0 papel do nutricionista nos Núcleos de Apoio à Saúde da Família-NASF. Rev APS 18(2): 248-255.

12. Araujo MC, Dias JMD, Vasconcelos KSS, Medeiros APP, Santos CM, et al. (2014) Impacto das condições clínicas e funcionais na qualidade de vida de idosas com obesidade. Fisioter Pesq 21(4): 372-377.

13. Dryman MT, Gardner S, Weeks JW, Heimberg RG (2016) Social anxiety disorder and quality of life: how fears of negative and positive evaluation relate to specific domains of life satisfaction. J Anxiety Disord 10(38): $1-8$.

14. Greenberger D, Padesky CA (1999) A mente vencendo o humor. Porto Alegre: Artmed.

15. Fleck MPA, Louzada S, Xavier M, Chachamovich E, Vieira G, et al. (2000) Aplicação da versão em português do instrumento abreviado de avaliação da qualidade de vida "WHOQOL-bref". Rev Saúde Pública 34(2): 178-183.

16. The WHOQOL Group (1998) Development of the World Health Organization WHOQOL-BREF: quality of life assessment. Psychol Med 28(3): 551-558.

17. Piantino CB, Cunha JC, Silva MCA, Almeida KM (2017) Parâmetros bioquímicos: associação com o estado nutricional e presença de patologia. RBONE 11(62): 86-93.

18. Santos RO, Ferreira LS, Carvalho FLO, Soares APG, Pereira RSF (2016) Fatores que influenciam a baixa adesão masculina ao atendimento prestado pela estratégia de saúde da família sede II do município de Sítio do Quinto/BA. Rev Saúde UniAGES1(1): 58-87.

19. Oliveira-Costa MS, Amorim ACCLÁ, Cadaxa AG, Mendonça AVM (2016) Promoção da saúde da mulher brasileira e a alimentação saudável: vozes e discursos evidenciados pela Folha de SP. Ciênc Saúde Coletiva 21(6): 1957-1964.

20. Turcato TD, Lima CP, Serralta FB (2017) Obesity, personality traits and psychological distress: a case control study. Quaderns de Psicologia 19(1): 59-71.

21. Andrade LHSG, Gorenstein C (1988) Aspectos gerais das escalas de avaliação de ansiedade. Revista de Psiquiatria Clínica 25(6): 285-290.

22. Carvalho IG, Bertolli ES, Paiva L, Rossi LA, Dantas RAS, Pompeo DA (2016) Ansiedade, depressão, resiliência e autoestima em indivíduos com doenças cardiovasculares. Rev Latino-Am Enfermagem 24: e2836.

23. Gonzaga LRV, Silva AMB, Enumo SRF (2016) Ansiedade de provas em estudantes do Ensino Médio. Psicol Argum 34(84): 76-88.

24. Möller-Leimkühler AM (2007) Gender differences in cardiovascular disease and comorbid depression. Dialogues Clin Neurosci 9(1): 71-83.

25. Palmeira CS, Garrido LMM, Lima MLL, Guimarães AC, Ladeia AMT (2016) Percepções acerca da condição de saúde de pessoas com obesidade. Rev Rene 17(5): 724-731.

26. Schultheisz TSV, Aprile MR (2013) Autoestima, conceitos correlatos e avaliação. Revista Equilíbrio Corporal e Saúde 5(1): 36-48.

27. Tavares TB, Nunes SM, Santos MO (2010) Obesidade e qualidade de vida: revisão da literatura. Rev Med Minas Gerais 20(3): 359-366.

\section{Your subsequent submission with Crimson Publishers will attain the below benefits}

International License

For possible submission use the below is the URL

Submit Article 